\title{
Formulation and evaluation of lecithin organogel for treatment of arthritis
}

\author{
Mahendra Prasad Jatav *, Suman Ramteke \\ School of Pharmaceutical Sciences, Rajiv Gandhi Proudyogiki Vishwavidyalaya, Bhopal (M. P.) Airport Bypass Road, \\ Gandhi Nagar, Bhopal (M. P.)- 462036 \\ *Corresponding author E-mail: mpjatav07@gmail.com
}

Copyright $\odot 2015$ Mahendra Prasad Jatav, Suman Ramteke. This is an open access article distributed under the Creative Commons Attribution License, which permits unrestricted use, distribution, and reproduction in any medium, provided the original work is properly cited.

\begin{abstract}
Background: Arthritis is a disease of the joint that involves inflammation of one or more joints. Topical administration of NSAIDs could deliver lornoxicam to the site of action in rheumatic diseases, which would reduce the gastrointestinal complications and side effects of the drug.

Methods: In this method, the oily phase was prepared by dispersing the specific amount (ratio; 40:60) of purified lecithin at room temperature in isopropyl myristate as dispersing and emulsifying agent. The aqueous phase of polypropylene was prepared by dispersing a weighed amount of polypropylene and glycerol in water. It was stored at 2$4 \mathrm{oC}$ overnight for the effective dissolution. The aqueous phase was slowly added in oily phase with stirring at $400 \mathrm{rpm}$ using a mechanical stirrer. The prepared organogel of lornoxicam were evaluated for its appearance, organoleptic characteristic, viscosity, gelation temperature, drug content and in vitro release study. In vivo evaluation for analgesic activity of formulation was carried out in terms of skin irritation study, hot plate method; writhing test and edema paw induce method.

Results: The drug content of organogel formulations was found in the range of $92.43 \pm 2.10-97.93 \pm 0.31 \%$ indicating uniform distribution of drug through the base and no interaction of drug with component of base. Posthoc Dunnet's ttest by employing statistical software, GraphPad InStat 3. It's shown differences between groups were considered significant at $\mathrm{P}<0.05$.

Conclusion: The transdermal organogel formulation of lornoxicam could provide significant anti-inflammatory and antirheumatic activity when applied topically and was observed to be functional for topical delivery of lornoxicam.
\end{abstract}

Keywords: Lornoxicam; Lecithin; Organogel; Arthritis; Topical Delivery; NSAIDS.

\section{Introduction}

Arthritis is frequently accompanied by joint pain, which is referred to as arthralgia. The disease is symmetrical and can lead to severe deformity in a few years if not treated. Lornoxicam (chlortenoxicam) is a strong analgesic and antiinflammatory NSAID of the oxicam class with better tolerability profile when compared to other NSAIDs. It has been shown to be effective in the treatment of postoperative pain and rheumatoid arthritis. Lornoxicam has short half-life of 3-4 hours, $\log$ P value 1.8-2.5 and molecular weight of $371.82 \mathrm{~g} / \mathrm{mol}$, which makes it potential candidate for transdermal drug delivery [1]. Skin is a natural barrier against the penetration of most drugs [2], and the ability of drug to penetrate the skin epidermis, dermis, and subcutaneous fat layers depend on the properties of the drug and the carrier base [3]. The topical administration of drugs, in order to achieve optimal cutaneous and percutaneous drug delivery has recently gained an importance because of various advantages such as ease of administration noninvasive, better tolerated and compliance, local enhanced transdermal delivery, avoidance of local gastrointestinal toxicity, avoidance of first-pass metabolism of drugs. In search of a delivery vehicle to deliver the medicament into the skin layers (cutaneous delivery) or through the skin and into the systemic circulation varied kinds of formulation systems and strategies have been evolved. The topical delivery has been attempted and made successful using several lipid-based systems viz e., 
liposomal formulations [4-6], nanostructured lipid carrier [7-8], lipid microemulsions [9], solid lipid microparticles [10], elastic liposomes or transfersomes [11], ethosomes [12-13] and lipid cubic phases [14-15] etc. In recent development; phospholipids in conjunction with some other additives have been shown to provide a very promising topical drug delivery vehicle known as lecithin organogels (LOs) [16-17]. The organogels are gels based on nonaqueous liquids, which have been mentioned in various pharmacopoeias as useful topical deliveries for lipophilic drugs [18]. They not only exert a local effect but also are capable of achieving a systemic effect via transdermal absorption, when their lipophilic nature and occlusive effect are potentiated by the presence of a penetration enhancer.

Lecithin organogels are thermodynamically stable, clear, viscoelastic, biocompatible, and isotropic gels composed of phospholipid, appropriate organic solvent, and a polar solvent. [17-18] Lecithin organogels, consist of a 3-dimensional network of entangled reverse cylindrical (polymer-like) micelles, which immobilizes the continuous or macroscopic external organic phase, thus turning a liquid into a gel. The formulation of a 3-dimensional network in the organogel is the result of transition at the micellar level in a low viscous Newtonian liquid consisting of lecithin micelles in nonpolar organic liquid. This spherical reverse micellar state of lipid aggregates turns on to form elongated tubular micelles with the addition of water and subsequently entangles to form a temporal 3-diamensional network in the solution bulk, the latter serves to immobilize the external organic phase, thus producing a gel form or the jelly-like state of the initial non-viscous solution. However, the transparency and optical isotropy of the organogel remains as before. These systems can also be called as polymer-like micelles or wormlike or threadlike micelles [19].

The traditional topical drug-delivery systems like emulsion and suspension have various limitations such as instability and minimal systemic absorption of drug. On other hands, the conventional dosage forms of NSAIDs are at increased risk for serious gastrointestinal complications, when administered through oral route. However topical administration of NSAIDs offers the advantage of local enhance drug delivery to affected tissues with reduced bioavailability as well as incidence of systemic adverse effects, such as peptic ulcer disease and gastrointestinal hemorrhage. Therefore, in the present work, topical organogel of lornoxicam is selected as the alternative route to oral delivery in order to improve its penetration ability and overcome the problems related with oral route.

In present work an attempt was made to prepare lornoxicam entrapped lecithin organogel of phospholipids (lecithin) propylene glycol and isopropyl myristate to transport the drugs in to and across the skin. The developed topical preparation could effectively deliver lornoxicam to the site of action in rheumatic diseases, which will effectively reduce the gastrointestinal side effects of the drug.

\section{Material and methods}

Lornoxicam was received as a gift sample from Aristo Pharmaceuticals, Baddi, India. The lecithin was procured from Ruchi Soya Pvt. Ltd. Indore, India. Isopropyl myristate, propylene glycol and sorbic acid were purchased from CDH Pvt. Ltd., Delhi, India. All other chemicals were of analytical grade.

The experiment protocol was approved by the institutional ethics committee of Truba Institute of Pharmacy, Bhopal and as per CPCSEA guidelines (approval no. 1196/a/08/CPCSEA).

\section{Experimental work}

\subsection{Method of preparation of Lecithin organogel}

In present work lornoxicam containing lecithin organogel was prepared by method established by Scartazzini and Luisi in 1988. [20]; with slight modification. In this method the oily phase was prepared by dispersing the specific amount (ratio; 40:60) of purified lecithin at room temperature in isopropyl myristate as dispersing and emulsifying agent. The mixture was kept overnight for complete dissolution of lecithin then the sorbic acid was added as preservative in this solution and finally lornoxicam was dissolved in oily phase. The aqueous phase of polypropylene was prepared by dispersing a weighed amount of polypropylene and glycerol in water. The dispersion was stored in a refrigerator at 2-4 oC overnight for the effective dissolution. The aqueous phase was slowly added in oily phase with stirring at $400 \mathrm{rpm}$ using a mechanical stirrer. The various formulations of lecithin organogel developed with different compositions are shown in table-1.

\subsection{Characterization of organogel}

The lecithin organogels prepared were characterized for following parameters.

Physical evaluation of organogels

Organoleptic characteristics: Each formulation was tested for color, odor, texture and phase separation as well as feels upon application (stiffness, grittiness, greasiness and tackiness). The results are given in the table-1.

Homogeneity test: - A small quantity of each gel was pressed between the thumb and the index finger in order to notice the consistency of cream that any coarse particles being attached or detached on the finger. The results are given in the table-1. 
Occlusiveness: - Prepared gel was taken in vial and visually observed weather it is occlusive or not. The observations are given in the table-1.

PH determination: The $\mathrm{pH}$ of organogels was determined using $\mathrm{pH}$ meter (Systronic $\mathrm{pH}$ system 361) which was calibrated before each use with buffered solutions at $\mathrm{pH} 4$ and 7. A solution containing $1 \mathrm{gm}$ of organogel in $30 \mathrm{ml}$ of neutralized distilled water was prepared and subjected to $\mathrm{pH}$ measurement [21]. The results are given in table-1.

Rheological studies [22]:- Rheological studies were performed with a thermostatically Fungilab Viscometer by using concentric cylinder spindle $61(\mathrm{~L} 4)$ at $100 \mathrm{rpm}$ and temperature $25 \mathrm{o} \mathrm{C}$. The results are given in table-1.

Drug content: - The content of lornoxicam in the formulations was determined as per method described by Willimann and Luisi (1991) [23]. Accurately weighed gel (1g) was diluted with $100 \mathrm{ml}$ of $0.1 \mathrm{~N} \mathrm{NaOH}$ and analyzed spectrophotometrically at $376.5 \mathrm{~nm}$ for lornoxicam content and are shown in table-1.

Gel Transition Temperature: - Gelation temperature, defined as the temperature at which the liquid phase makes a transition to gel. The phase behavior of organogels varies on changing the temperature conditions. The phase transition temperature (PTT) (i.e., sol-to-gel, TSG, or gel-to-sol, TGS) gives insight into the nature of microstructures that form the gelling cross-linked network. The phase transition temperature also helps in optimizing the organogel composition [24]. The gel transition temperature was determined in a test tube enclosing $0.25 \mathrm{~g}$ of gel and observed over the temperature range $2-30 \mathrm{o}$ C. The change from sol to gel was said to have occurred when the meniscus would not move immediately upon tilting the test tube to 90o. The temperature was raised slowly with the help of water bath and the temperature at which the physical state of the formulation was changed was regarded as the gelation temperature. The observations are given in table-1.

Swelling Index Study of Organogel: - Swelling of the polymer depends on the concentration of the polymer, ionic strength and the presence of water. To determine the swelling index of prepared topical gel, one gm of gel was taken on porous aluminum foil and then placed separately in a $50 \mathrm{ml}$ beaker containing $10 \mathrm{ml} 0.1 \mathrm{~N} \mathrm{NaoH}$. Then samples were removed from beakers at different time intervals and kept it on dry.

Place for some time after that it was reweighed. Swelling index was calculated as follows [25-26]. The results are given in table-1.

Swelling Index $(\mathrm{SW}) \%=[(\mathrm{Wt}-\mathrm{Wo}) / \mathrm{Wo}] \times 100$.

Where, (SW) $\%$ = Equilibrium percent swelling,

$\mathrm{Wt}=$ Weight of swollen gel after time $\mathrm{t}$,

Wo $=$ Original weight of gel at zero time.

\subsection{In vitro drug release studies}

The different formulations were subjected to in vitro drug release studies. The release of lornoxicam from lecithin organogel was determined as a function of time in phosphate buffer saline ( $\mathrm{pH}$ 7.4) using dialysis membrane-150 (Himedia) the release profile of lornoxicam from different formulations are given in table no 01 .

In vivo studies.

\subsection{Analgesic activity of lornoxicam organogel}

The analgesic activity of lornoxicam entrapped formulation was determined on albino rats of four months, of both sexes, weighing between 150 to $170 \mathrm{gm}$. The animals were acclimatized to the standard laboratory conditions in cross ventilated animal house at temperature $25 \pm 2{ }^{\circ} \mathrm{C}$ with relative humidity $44-56 \%$ and light and dark cycles of $12: 12$ hours. All rats were fed with standard pallet diet and water ad libitum during experiment. The experiment protocol was approved by the institutional ethics. The experiment for analgesic activity was performed in terms of Skin irritation study, Hot Plate method; Acetic acid induced writhing test and Carrageenan-induced paw edema method.

Skin irritation study: - The purpose of this test was to determine the skin irritation potential of lornoxicam incorporated into organogel to the intact skin of albino rats.

Hot Plate method: - Eddy's Hot Plate Analgesiometer was used for screening of analgesic drug properties and to evaluate alterations of animal pain sensitivity [27-28].

Acetic acid induced writhing test: - A noxious substance is injected in the abdominal cavity (intraperitoneally) of the animal causing severe abdominal pain and contraction of abdominal musculature (writhing).

Carrageenan-induced paw edema: - the evaluation of Antiedematogenic activity was carried out by rat-paw edema test. Albino rats $(\mathrm{n}==4)$ ) wereerandomizeddanddassigneddtoodifferenttexperimentallgroups.Edemaainhibitionnratee (I)) afterrdifferentttreatmentsswasscalculateddusinggfollowingg :

$$
\begin{aligned}
& \mathrm{E}=\mathrm{Vt}-\mathrm{Vo} / \mathrm{Vo} \\
& \mathrm{I} \%=\mathrm{Ec}-\mathrm{Et} / \mathrm{Ec} \times 100,
\end{aligned}
$$

Where $\mathrm{VO}$ is the mean paw volume before $1 \%$ carrageenan $(\mathrm{w} / \mathrm{v})$ injection, $\mathrm{Vt}$ is the mean paw volume after $1 \%$ carrageenan (w/v) injection, Ec is the edema rate of the control group, and Et is the edema rate of the treated group [29]. 


\section{Results and discussion}

The aim of present work is to develop pharmaceutically acceptable lecithin organogel for topical delivery of lornoxicam with improved therapeutic performance by their penetration enhancing property. In order to achieve this objective, the formulations were prepared with lecithin (95\%), isopropyl myristate and propylene glycol as a cosurfactant. The developed formulations were characterized for their organoleptic properties, $\mathrm{pH}$, swelling index, viscosity, gel transition temperature, in vitro drug release studies and analgesic activity of formulation.

The physiological observation shows that organogel formulations were washable, yellowish in color with no phase separation, smooth in feel, and showed no clogging, which indicate good texture of system. Freedom from grittiness reflects the degree of acceptability of lornoxicam formulation by the patients.

The in vivo studies shown the better reducing inflammatory activities of organogel compare the standard formulation. The activities performed by the writhing test, hot plate method, and skin irritation study and carrageenan-induced paw edema method.

\subsection{Effect of $\mathrm{pH}$}

There was no significant difference in $\mathrm{pH}$ between the batches. The $\mathrm{pH}$ of all the formulations was around the skin $\mathrm{pH}$ reflecting no risk of skin irritation. It was determined by using $\mathrm{pH}$ meter (Systronic $\mathrm{pH}$ system 361) (Table.1).

\subsection{Rheological measurements}

It was observed that on increasing the concentration of lecithin, viscosity increases from 5261 to 5581 poise.. The increase in viscosity with increase in concentration of lecithin (table-1) was might be due to formation of complex network as in gel, consistency depends on percentage of solid in relation to liquid.

\subsection{Drug content}

The drug content of organogel formulations was found in the range of $92.43 \pm 2.10-97.93 \pm 0.31 \%$ indicating uniform distribution of drug through the base and no interaction of drug with component of base. The drug contents of all formulations are depicted in table- 1 .

\subsection{Effect on swelling index}

All the formulations showed swelling index in the range of 71-96\% depicted in table- 1 . It was observed that increase in percentage of organogelator decrease the swelling index.

\subsection{Effect on Gel transition temperature}

On increasing the viscosity of the system; gel transition temperature decreases and stronger is the work of adhesion. The transition temperatures of formulations are given in table-1.

\subsection{In vitro drug release studies}

The effects of lecithin concentration on the release rate of lornoxicam from organogels formulation were evaluated in phosphate buffer ( $\mathrm{pH}-7.4)$. The The lornoxicam release was found to be decrease with an increase in lecithin content, an inverse correlation existed between the release rate and the gel viscosity values. But a significant decrease in lornoxicam release was obtained as the lecithin concentration was further increased from $5-10 \%$ in the formulations LOF6, LOF7, LOF8, and LOF9 to LOF10.

This effect may be due to a decreased in thermodynamic activity of concentrations, there is more extensive entanglement of long cylindrical micelles with each other, forming a network-like structure with a very high viscosity. The entrapment of the drug within this network lowers the amount of free drug available for release, causing a decrease in release rate of lornoxicam across the membrane. Further increase in concentration of organogelator decrease cumulative percentage drug release which might be due to extensive entanglement of long cylindrical micelles with each other, forming network like structure with very high viscosity. It's shown in figure 1. 
Table 1: Characterization of Lecithin Organogel System

\begin{tabular}{|c|c|c|c|c|c|c|c|c|c|c|c|c|c|}
\hline \multirow{3}{*}{\multicolumn{2}{|c|}{$\begin{array}{l}\text { Formulation } \\
\text { code }\end{array}$}} & \multirow[b]{3}{*}{$\mathrm{pH}$} & \multirow{3}{*}{$\begin{array}{l}\text { Drug } \\
\text { content } \%\end{array}$} & \multirow{3}{*}{$\begin{array}{l}\text { Swell } \\
\text { ing } \\
\text { index } \\
\% \\
\text { after } \\
1 \text { hrs }\end{array}$} & \multirow{3}{*}{$\begin{array}{l}\text { Visco } \\
\text { sity } \\
\text { at } 10 \\
\text { rpm } \\
\text { (poise) }\end{array}$} & \multirow{3}{*}{$\begin{array}{l}\text { Gelation } \\
\text { temp }\end{array}$} & \multicolumn{7}{|c|}{ Physiological observation } \\
\hline & & & & & & & \multirow[t]{2}{*}{$\begin{array}{l}\text { Wash } \\
\text { ability }\end{array}$} & \multirow{2}{*}{$\begin{array}{l}\text { Occlu } \\
\text { sive } \\
\text { ness }\end{array}$} & \multirow{2}{*}{$\begin{array}{l}\text { Homo } \\
\text { gene } \\
\text { city }\end{array}$} & \multicolumn{4}{|c|}{ Organoleptic Characteristics } \\
\hline & & & & & & & & & & Color & Odour & $\begin{array}{l}\text { Phase } \\
\text { separa } \\
\text { tion }\end{array}$ & $\begin{array}{l}\text { Feel } \\
\text { upon } \\
\text { appli } \\
\text { cation }\end{array}$ \\
\hline LOF1 & $30: 70$ & $7.02 \pm 0.2$ & $97.93 \pm 0.31$ & 87 & 5483.1 & 30.3 & No & Yes & Yes & Yellow & No & No & Smooth \\
\hline LOF2 & $40: 60$ & $6.88 \pm 0.4$ & $97.87 \pm 1.03$ & 96 & 5567.2 & 30.1 & Yes & Yes & Yes & Yellow & No & No & Smooth \\
\hline LOF3 & $50: 50$ & $7.21 \pm 0.1$ & $96.87 \pm 0.54$ & 84 & 5028.6 & 24.9 & No & Yes & Yes & Yellow & No & No & Smooth \\
\hline LOF4 & $60: 40$ & $7.15 \pm 0.2$ & $95.05 \pm 1.54$ & 82 & 5492.4 & 27.8 & Yes & Yes & Yes & Yellow & No & No & Gritty \\
\hline LOF5 & $70: 30$ & $6.88 \pm 0.3$ & $96.62 \pm 0.25$ & 86 & 5362.6 & 26.4 & No & Yes & Yes & Yellow & No & Yes & Smooth \\
\hline \multicolumn{14}{|c|}{ Lecithin : IPM } \\
\hline LOF6 & $30: 70$ & $6.13 \pm 0.2$ & $96.37 \pm 0.12$ & 88 & 5261.7 & 25.3 & Yes & Yes & Yes & Yellow & No & No & Smooth \\
\hline LOF7 & $40: 60$ & $7.01 \pm 0.4$ & $95.18 \pm 2.00$ & 91 & 5481.8 & 27.8 & Yes & Yes & Yes & Yellow & No & No & Smooth \\
\hline LOF8 & $45: 55$ & $7.00 \pm 0.1$ & $93.37 \pm 1.54$ & 87 & 5475.2 & 27.0 & Yes & Yes & Yes & Yellow & No & No & Smooth \\
\hline LOF9 & $50: 50$ & $6.87 \pm 0.1$ & $94.81 \pm 1.78$ & 80 & 5568.2 & 27.0 & Yes & Yes & Yes & Yellow & No & No & Stiffness \\
\hline LOF10 & $60: 40$ & $6.98 \pm 0.2$ & $94.18 \pm 1.01$ & 89 & 5477.7 & 23.8 & No & Yes & Yes & Yellow & No & Yes & Gritty \\
\hline \multicolumn{14}{|c|}{$\begin{array}{l}\text { Propylene } \\
\text { Glycol (ml) }\end{array}$} \\
\hline LOF11 & 2 & $7.13 \pm 0.1$ & $93.25 \pm 1.64$ & 82 & 5367.2 & 28.4 & No & Yes & Yes & Yellow & No & No & Smooth \\
\hline LOF12 & 4 & $5.98 \pm 0.3$ & $93.00 \pm 1.51$ & 71 & 5423.7 & 30.2 & Yes & Yes & Yes & Yellow & No & No & Stiffness \\
\hline LOF13 & 6 & $7.02 \pm 0.2$ & $95.00 \pm 0.21$ & 85 & 5532.6 & 30.3 & Yes & Yes & Yes & Yellow & No & No & Smooth \\
\hline LOF14 & 8 & $6.88 \pm 0.4$ & $92.43 \pm 2.10$ & 81 & 5532.8 & 30.1 & Yes & Yes & Yes & Yellow & No & No & Gritty \\
\hline LOF15 & 10 & $7.21 \pm 0.1$ & $93.68 \pm 1.56$ & 86 & 5581.6 & 32.5 & Yes & Yes & Yes & Yellow & No & Yes & Smooth \\
\hline
\end{tabular}

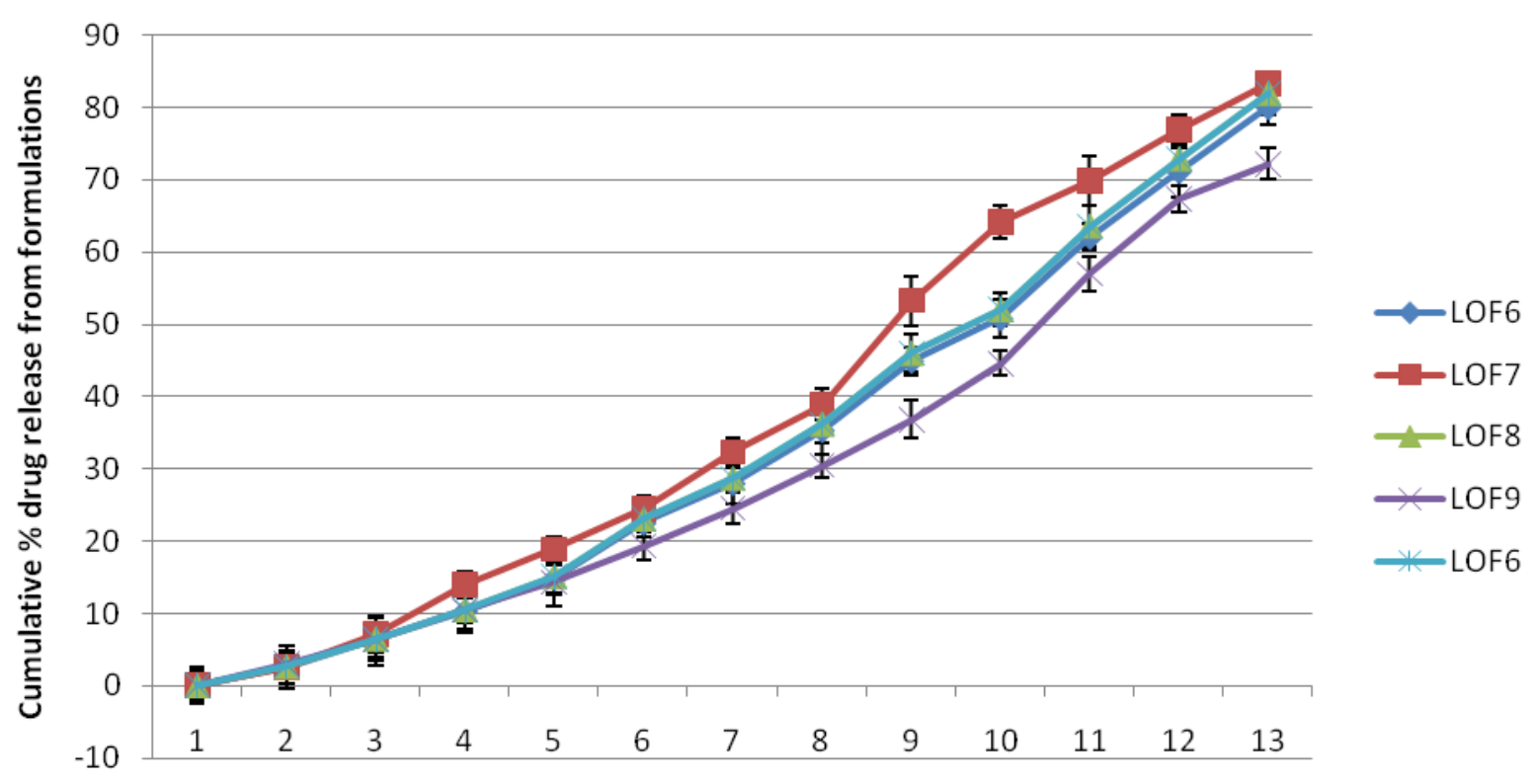

Time in (Hrs)

Fig. 1: Cumulative Effect of Oil: Water Concentration Ratio on in-Vitro Release Profile of Lornoxicam in Phosphate Buffer PH 7.4 at $37 \pm 2 \mathrm{OC}$ $(\Lambda \max 376.5 \mathrm{~nm}$

\subsection{Analgesic activity of Lornoxicam organogel}

The purpose of this study was to examine the efficacy of prepared organogel formulation as a topical drug delivery system, which enhances drug diffusion inside the deeper layer of skin and could reduce systemic side effects of drug. In present work the effect of optimized lornoxicam organogel formulation on basal reaction time (hot plate method), ratpaw edema test, and skin irritation study and on acetic acid induced abdominal writhing in albino rats was evaluated. The animals were divided into three groups, each consisting of four animals. The hairs of animals were shaved in two $\mathrm{cm} 2$ areas with the help of hair removing cream in interscapular region. For study of the lornoxicam organogel was applied topically. The treated areas of animals were protected by using nylon mesh, which was supported by plastic squares having small pores. Treated animals were kept in separate cages and housed in standard laboratory conditions. Group (I) was kept as a control (without treatment); group (II) was kept as standard; treated with marketed formulation of diclofenac sodium gel (four $\mathrm{mg} / \mathrm{kg}$ ) which was topically applied on the shaved surface; group (III) was considered as 
test group which was treated with organogel formulation of lornoxicam $(4 \mathrm{mg} / \mathrm{kg})$. The formulation was topically applied on shaved surface, respectively.

\subsection{Skin irritation study}

The purpose of this test was to determine the skin irritation potential of lornoxicam incorporated into organogel to the intact skin of albino rats. The hairs were removed from the back of rats using hair remover cream and area of two $\mathrm{cm} 2$ diameter was marked on both sides. One side served as control while other as test and animals were used after $24 \mathrm{hrs}$. The gel was applied $(100 \mathrm{mg} / \mathrm{rat})$ once a day for seven days, and sight was covered with cotton bandage. The rats were observed for sensitivity and the reaction if any. No sensitivity and no reaction of any type were observed and are given in table 2 and graded as.

Table 2: Effect of Lornoxicam Organogel Formulation on Reaction Time of Rats in Skin Irritation Study

\begin{tabular}{ll}
\hline Time (hrs) & Activity \\
\hline 0 & No reaction \\
0.5 & No reaction \\
1 & No reaction \\
2 & No reaction \\
3 & No reaction \\
4 & No reaction \\
\hline
\end{tabular}

\subsection{Hot plate method}

The hot plate consists of an electrically heated surface. The temperature was controlled for $50^{\circ}$ to $55^{\circ} \mathrm{C}$. The rats were placed individually on the hot plate and the time until either licking or jumping occurs was recorded by a stop-watch. The results in table 3; revealed that applied lornoxaicam organogel formulation produced significant analgesic action in terms of increasing the time of paw licking and jump response. The results of organogel formulation was compared with standard marketed formulation (Volini gel, Ranbaxy) as are shown table 3.

Table 3: Effect of Lornoxicam Organogel Formulation on Reaction Time of Rats in Hot Plate Method.

\begin{tabular}{|c|c|c|c|c|c|c|c|c|c|}
\hline \multirow[t]{2}{*}{ Group } & \multirow{2}{*}{$\begin{array}{l}\text { Treat } \\
\text { ment }\end{array}$} & \multicolumn{4}{|c|}{$\begin{array}{l}\text { Reaction time in sec. } \\
\text { Paw licking }\end{array}$} & \multicolumn{4}{|c|}{ Jump response } \\
\hline & & $15 \mathrm{~min}$ & $30 \mathrm{~min}$ & $45 \mathrm{~min}$ & $60 \mathrm{~min}$ & $15 \mathrm{~min}$ & $30 \mathrm{~min}$ & $45 \mathrm{~min}$ & $60 \mathrm{~min}$ \\
\hline I & Control & $38.5 \pm 0.4$ & $32.2 \pm 0.4$ & $35.4 \pm 1.3$ & $38.3 \pm 1.4$ & $75.3 \pm 1.7$ & $79.0 \pm 1.1$ & $72.6 \pm 0.9$ & $75.6 \pm 0.6$ \\
\hline II & Standard & $46.6 \pm 0.6$ & $49.4 \pm 1.2 * *$ & $62.6 \pm 2.3 * *$ & $68.3 \pm 0.5 * *$ & $89.7 \pm 1.5$ & $95.6 \pm 0.7 * *$ & $106.5 \pm 2.3 * *$ & $112.7 \pm 1.8 * *$ \\
\hline III & Test & $45.4 \pm 0.7$ & $47.1 \pm 2.5 * *$ & $50.8 \pm 1.5 * *$ & $55.8 \pm 0.4 * *$ & $81.0 \pm 0.7$ & $85.6 \pm 0.4 * *$ & $97.8 \pm 0.4 * *$ & $109.4 \pm 0.9 * *$ \\
\hline
\end{tabular}

(Values are mean \pm SEM from a group of four animals. $* \mathrm{p}<0.05$, $* * \mathrm{p}<0.01$ when all treatment groups compared to group-I $($ control). $(*=95 \%, * *=$ $99 \%$ purity)

\subsection{Acetic acid induced writhing test}

Acetic acid in a concentration of $1 \% \mathrm{v} / \mathrm{v}$, one $\mathrm{ml} / \mathrm{kg}$ was injected intraperitoneal to animals of each group. The animals were placed individually into glass beakers and are allowed for five minimums to elapse. The animals were observed for a period of ten minimums and the number of writhes was recorded for each animal. Wriths were indicated by stretching of the abdomen with simultaneous stretching of at least one hind limb. The percent inhibition of wriths was calculated and compared with test formulation of lornoxicam organogel and the control formulation of marketed diclofenac sodium gel it's shown in table-4. The lornoxaicam organogel formulation produced decreasing wriths and shows similar effect as marketed standard formulation.

Table 3: Effect of Lornoxicam Organogel Formulation on $1 \%$ Acetic Acid Induced Wriths in Rats.

\begin{tabular}{llll}
\hline Group & Treatment & Wriths (Mean \pm SEM) & \%Inhibition of Wriths \\
\hline I & Control & $8.0 \pm 0.32$ & - \\
II & Standard & $4.5 \pm 0.23 * *$ & 43.75 \\
III & Test & $5.0 \pm 0.12 * *$ & 37.5 \\
\hline
\end{tabular}

(Values are mean \pm SEM from a group of four animals. * $\mathrm{p}<0.05, * * \mathrm{p}<0.01$ when all treatment groups compared to group-I (control). )

\subsection{Carrageenan-induced paw edema}

Carrageenan-induced paw edema is the standard experimental model for acute inflammation. Carrageenan is the phlogistic agent of choice for testing anti-inflammatory drugs as it is not known to be antigenic and is devoid of 
apparent systemic effects. Moreover, the experimental model exhibits a high degree of reproducibility. The development of edema has been described as biphasic.(30) [84] The first phase (1h) is mediated through the release of serotonin and histamine, and the second phase (over $1 \mathrm{~h}$ ) is mediated by prostaglandins, cyclooxygenase products. Continuity between the two phases is provided by kinins (31).

Acute inflammation was caused by injecting $0.1 \mathrm{ml}$ of $1 \%(\mathrm{w} / \mathrm{v})$ carrageenan in saline into the sub-plantar region of the right hind paw of each rats. The paw volume was measured plethysmometrically at $1 \mathrm{~h}, 2 \mathrm{~h}, 3 \mathrm{~h}, 4 \mathrm{~h}, 5 \mathrm{~h}$ and $6 \mathrm{~h}$ after the carrageenan injection. Edema was expressed as mean paw volume. [83] The lornoxaicam organogel formulation produced Anti-inflammatory action and decreased paw volume of rats as compared marketed standard formulation (Volini gel, Ranbaxy) as are shown in table-5.

Table 5: Effect of Lornoxicam Organogel Formulation on Carrageenan Induced Paw Edema.

\begin{tabular}{|c|c|c|c|c|c|c|c|c|}
\hline \multirow{2}{*}{ Group } & \multirow{2}{*}{ Treatment } & \multicolumn{6}{|c|}{ Paw volume (ml) } & \multirow{2}{*}{$\%$ Inhibition } \\
\hline & & $\mathrm{Oh}$ & $1 \mathrm{~h}$ & $2 \mathrm{~h}$ & $3 h$ & $4 \mathrm{~h}$ & $5 \mathrm{~h}$ & \\
\hline I & Control & $0.5 \pm 0.02$ & $0.8 \pm 0.04$ & $1.0 \pm 0.03$ & $1.2 \pm 0.07$ & $1.5 \pm 0.06$ & $1.6 \pm 0.08$ & - \\
\hline II & Standard & $0.5 \pm 0.03$ & $0.6 \pm 0.05$ & $0.7 \pm 0.04$ & $0.8 \pm 0.05$ & $0.7 \pm 0.03$ & $0.6 \pm 0.09$ & 62.5 \\
\hline III & Test & $0.5 \pm 0.05$ & $0.7 \pm 0.02$ & $0.8 \pm 0.01$ & $0.8 \pm 0.03$ & $0.8 \pm 0.05$ & $0.7 \pm 0.03$ & 56.25 \\
\hline
\end{tabular}

In present experimental studies revels that lornoxicam organogel formulation (at dose $4 \mathrm{mg} / \mathrm{kg}$ topically) produced significant analgesic action by increasing the time of paw licking and jump response in the model of Hot plate and decreasing wriths in acetic acid induced pain. Anti-inflammatory action produced by lornoxicam organogel formulation was found significant decreasing the paw volume in the model of carrageenan-induced paw edema.

\subsection{Statistical analysis}

All the values are expressed as mean \pm standard error of mean (S.E.M.) and analyzed for ANOVA and posthoc Dunnet's t-test by employing statistical software, GraphPad InStat 3. Differences between groups were considered significant at P $<0.05$.

\section{Conclusion}

The transdermal organogel formulation of lornoxicam could provide significant anti-inflammatory and antirheumatic activity when applied topically and was observed to be functional for topical delivery of lornoxicam. The system will not only exert a local effect but also would be capable of achieving a systemic effect via transdermal absorption, and their effects are potentiated by the presence of a penetration enhancer. Prepared lornoxicam organogels containing lecithin, isopropyl myristate and polypropylene glycol were observed to be safe, stable, and cost-effective drug delivery system.

This delivery system particularly helpful for patients with gastrointestinal symptoms (e.g., nausea and vomiting) dizziness, increased drowsiness, headache, increased sweating, taste disorders, dry mouth, agitation, dyspepsia, diarrhoea, palpitation by targeted delivery of lornoxicam to the site of action. It has Thermo reversibility, Reduce pain effectively in arthritis, Easy to apply, Safe for long-term application, Enhance topical performance and biocompatibility, thermodynamically stable, the structural integrity maintained for longer time periods, Avoidance of the variation in the absorption and metabolism associated with oral administration, Avoidance of the risk and inconveniences of injection.

\section{Acknowledgement}

Authors would to acknowledge Aristo Pharmaceuticals, Baddi, India for providing lornoxicam as a gift sample. Authors would like to acknowledge school of pharmaceutical sciences, RGPV for providing all necessary facility during project work. Authors would also like to thanks Truba Institute of Pharmacy, Bhopal for providing facilities for animal studies.

\section{References}

[1] Rosenow D. A comparison of patientcontrolled analgesia with lornoxicam versus morphine in patients undergoing lumbar disk surgery. Anesthesia \& Analgesia (International Anesthesia Research Society), 1998; 86: 1045-1050.

[2] Naik A, Kalia YN, Guy RH. Transdermal drug delivery: overcoming the skin's barrier function. Pharm Sci Technol Today. $2000 ; 3: 318-26$. http://dx.doi.org/10.1016/S1461-5347(00)00295-9.

[3] Idson B, Lazarus J. Semisolids. In: The theory and practice of industrial pharmacy. Bombay, India: Vargehese Publishing Hou se; 1991. p. 534-63.

[4] Bhatia A, Singh B, Amarji B, Katare OP. Tamoxifen-Loaded liposomal topical formulation arrests hair growth in mice. Br J Dermatol Nurs. 2009.

[5] Gupta M, Goyal AK, Paliwal SR, Paliwal R, Mishra N, Vaidya B, et al. Development and characterization of effective topical liposomal system for localized treatment of cutaneous candiasis. J Liposome Res. 2010; 20 (4):341-50. http://dx.doi.org/10.3109/08982101003596125. 
[6] Dragicevic-Curic N, Winter S, Krajisnik D, Stupar M, Milic J, Graefe S, et al. Stability evaluation of temoporfin-loaded liposomal gels for topical application. J Liposome Res. 2010; 20 (1):38-48. http://dx.doi.org/10.3109/08982100903030263.

[7] Puglia C, Filosa R, Peduto A, de Caprariis P, Rizza L, Bonina F, et al. Evaluation of alternative strategies to optimize ketorolac transdermal delivery. AAPS PharmSciTech. 2006; 7 (3):E1-9. http://dx.doi.org/10.1208/pt070364.

[8] Ferderber K, Hook S, Rades T. Phosphatidyl choline-based colloidal systems for dermal and transdermal drug delivery. J Liposome Res. 2009; 19(4):267-77. http://dx.doi.org/10.3109/08982100902814006.

[9] Luciana BL, Hillary VDW, Hsin TL, Vijay V, Hsin KL, and Stan N, et al. Topical delivery of lycopene using microemulsions: enhanced skin penetration and tissue antioxidant activity. J Pharm Sci. 2009; 99(3):1346-57.

[10] Scalia S, Mezzena M, Iannuccelli V. Influence of solid lipid microparticle carriers on skin penetration of the sunscreen agent, 4methylbenzylidene camphor. J Pharm Pharmacol .2007; 59:1621-7. http://dx.doi.org/10.1211/ipp.59.12.0003.

[11] Jain SK, Gupta Y, Jain A, Rai K. Enhanced transdermal delivery of acyclovir sodium via elastic liposomes. Drug Deliv. 2006; 15:141-7. http://dx.doi.org/10.1080/10717540801952407.

[12] Maestrelli F, Capasso G, González-Rodríguez ML, Antonio M, Rabasco CG, Mura P. Effect of preparation technique on the properties and in vivo efficacy of benzocaine-loaded ethosomes. J Liposome Res. 2009; 19 (4):253-60. http://dx.doi.org/10.3109/08982100902788408.

[13] Bendas ER, Tadros MI. Enhanced Transdermal Delivery of Salbutamol Sulfate via Ethosomes. AAPS PharmSciTech 2007; 8 (4) Article 107 http://dx.doi.org/10.1208/pt0804107.

[14] Bender J, Simonsson C, Smedh M, Engström S, Ericson MB. Lipid cubic phases in topical drug delivery: visualization of skin distribution using two-photon microscopy. J Control Release. 2008; 129 (3):163-9. http://dx.doi.org/10.1016/j.jconrel.2008.04.020.

[15] Bender J, Ericson MB, Merclin N, Iani V, Rosen A, Engstrom S, et al. Lipid cubic phases for improved topical drug delivery in photodynamic therapy. J Control Release. 2005; 106:350-60. http://dx.doi.org/10.1016/j.jconrel.2005.05.010.

[16] Scartazzini R, Luisi PL. Organogels from lecithins. J Phys Chem. 1988; 92:829-833. http://dx.doi.org/10.1021/j100314a047.

[17] Schurtenberger P, Scartazzini R, Magid LJ, Leser ME, Luisi PL. Structural and dynamic properties of polymer-like reverse micelles. J Phys Chem. 1990; 94:3695-3701 http://dx.doi.org/10.1021/j100372a062.

[18] Martin, A., 1993. Coarse dispersions. In: Martin, A. (Ed.), Physical Pharmacy, fourth ed. William and Wilkins, USA, pp. 496-502.

[19] Shchipunov Y.A.; Dueerrschmidt T.; Hoffmann H. (2000), Endto end fusion of polymer like micellege in lecithin organogel under the action of an electric field, Langmuir, 16, 297-299. http://dx.doi.org/10.1021/la990810s.

[20] Shchipunov Y.A.; Dueerrschmidt T.; Hoffmann H.; (1999) Electroheological effects in lecithin organogels with water and glycerol. J. Colloid Interface Science; 212: 390-401. http://dx.doi.org/10.1006/jcis.1998.6046.

[21] Nasseri A.A.; Aboofazeli R.; Zia H.; and Needham T.E.; (2003) Lecithin stabilize microemulsion. I: Phase behavior studies. Iranian J. Pharm. Res., 2:59-61.

[22] Willimann H.; Luisi P.L.; (1991) Lecithin organogels as matrix for transdermal transport of drugs. Biochem Biophys Res Commun.; 177: 897900. http://dx.doi.org/10.1016/0006-291X(91)90622-E.

[23] Couffin-Hoarau A.C.; Motulsky A.; (2004) Insitu-forming pharmaceutical organogels based on the self-assembly of L-Alanine derivatives. Pharm Res; 21: 454-457. http://dx.doi.org/10.1023/B:PHAM.0000019299.01265.05.

[24] Kamel A.E.; Sokar M.; Naggar V.; Gamal S.A.; (2002) Chitosan and sodium alginate-based bioadhesive vaginal tablets, AAPS PharmSci.; 4: $1-7$.

[25] Mishra D.N.; Gilhotra R.M.; (2008) Design and characterization of bioadhesive in - situ gelling ocular insert of gatifloxacin sesquihydrate. Daru; $16: 1-8$.

[26] Vogel (2002) Drug Discovery and Evaluation Pharmacological Assays" 2nd Ed.

[27] Kukarni S.K. (2007) Hand book of experimental pharmacology 3rd edition, 125-126.

[28] Laithy H.M. and. Shaboury K.M. F. (2002). "The Development of Cutina Lipogels and Gel Microemulsion for Topical Administration of Fluconazole.” AAPS Pharm Sci. Tech. 3:E35.

[29] Radomska A.; Dobrucki R.; (2000) the use of some ingredients for microemulsion preparation containing retinol and its esters. International journal of Pharmaceutics, 196, 131-134. http://dx.doi.org/10.1016/S0378-5173(99)00436-6.

[30] Vinegar R; Schreiber W; Hugo R (1969), Biphasic development of carrageenin oedema in rats. Journal of Pharmacology and Experimental Therapeutics 166, 96-103.

[31] Vinegar R (1968), Quantitative studies concerning kaolin edema formation in rats. Journal of Pharmacology and Experimental Therapeutics, $161,389-395$ 